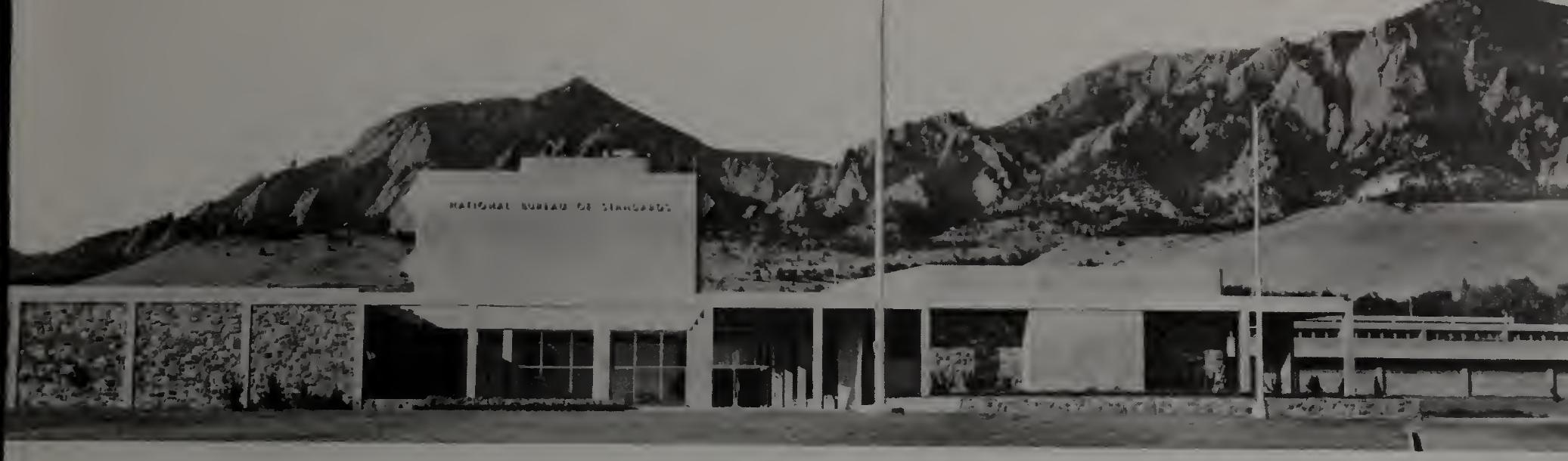

NBS REPORT

5550

THE COMPONENTS OF POWER APPEARING IN THE HARMONIC ANALYSIS OF A STATIONARY PROCESS

by

M. M. Siddiqui

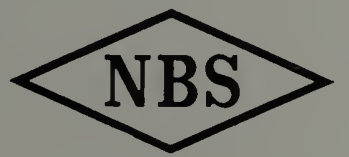

U. S. DEPARTMENT OF COMMERCE NATIONAL BUREAU OF STANDARDS

BOULDER LABORATORIES

Boulder, Colorado 


\section{THE NATIONAL BUREAU OF STANDARDS}

\section{Functions and Activities}

'The functions of the National Burcau of Standards are set forth in the Act of Congress, March 3, 1901, as amended by Congress in Public Law 619, 1950. These include the development and maintenance of the national standards of measurement and the provision of means and methods for making measurements consistent with these standards: the determination of physical constants and properties of materials; the development of methods and instruments for testing matcrials, devices, and structures; advisory services to Govermment Agencies on scientific and technical problems; invention and development of devices to serve special needs of the Government; and the development of standard practices, codes and specifications. The work includes basic and applied research, development, engineering, instrumentation, testing, evaluation, calibration services, and various consultation and information services. A major portion of the Bureau's work is performed for other Government Agencies, particularly the Department of Defense and the Atomic Energy Commission. The scope of activities is suggested by the listing of divisions and sections on the inside back cover.

\section{Reports and Publications}

The results of the Bureau's work take the form of either actual equipment and devices or published papers and reports. Reports are issued to the sponsoring agency of a particular project or program. Published papers appear either in the Bureau's own series of publications or in the journals of professional and scientific societies. The Bureau itself publishes three monthly periodicals, available from the Government Printing Office: The Journal of Research, which presents complete papers reporting technical investigations; the Technical News Bulletin, which presents summary and preliminary reports on work in progress; and Basic Radio Propagation Predictions, which provides data for determining the best frequencies to use for radio communications throughout the world. There are also five series of nonperiodical publications: The Applied Mathematics Series, Circulars, Handbooks, Building Materials and Structures Reports, and Miscellaneous Publications. 


\section{NATIONAL BUREAU OF STANDARDS REPORT}

NBS PROJECT 
NATIONAL BUREAU OF $S$ ments intended for use wit is subjected to additional e tion, or open-literature list mission is obtained in writin 25, D. C. Such permission been specifically prepared $i$
Approved for public release by the director of the National Institute of Standards and Technology (NIST) on October 9, 2015 or progress occounting docurorts is formally published it ication, reprinting, reproducis not authorized unless perau of Standards, Washington ncy for which the Report has upies for its own use. 
THE COMPONENTS OF POWER APPEARING IN THE HARMONIC ANALYSIS OF A STATIONARY PROCESS

by

M. M. Siddiqui

\section{INTRODUCTION}

Let $Y(t)$ be a real stationary process with mean zero and autocovariance function $C(t)=E Y(s) Y(s+t)$. Here Ex denotes the expected value of the random variable $x$ and we assume $C(t)$ to be finite for all values of $t$. Suppose we have a continuous record of $Y(t)$ over the time interval $(0, T)$ measured in seconds and we take $2 n+1$ equally spaced readings $Y_{0}, Y_{1}, \ldots, Y_{2 n}$ at times $t=0, \delta, 2 \delta, \ldots, 2 n \delta=T$ seconds. It is customary to represent the readings by the Fourier series

(1.1) $Y_{i}=a_{0}^{\prime}+\sum_{j=1}^{n}\left(a_{j}^{\prime} \cos \frac{2 \pi j i}{2 n}+\beta_{j}^{\prime} \sin \frac{2 \pi j i}{n}\right), i=0,1, \ldots, 2 n$, to estimate the power spectrum of the process $Y(t)$.

Assuming that the true representation of $Y(t)$ is given by

(1.2) $Y(t)=\sum_{j=1}^{\infty}\left(a *(j) \cos \frac{2 \pi j t}{T}+\beta *(j) \sin \frac{2 \pi j t}{T}\right)$

$$
+\sum_{m=2}^{\infty}\left(a *\left(\frac{1}{m}\right) \cos \frac{2 \pi t}{m T}+\beta *\left(\frac{1}{m}\right) \sin \frac{2 \pi t}{m T}\right) \text {. }
$$


it will be shown that the power ascribed to the frequency $\mathrm{j} / \mathrm{T}$ cycles per second (cps) in the analysis of (1.1) consists of three components:

(1) the true power in the frequency $\mathrm{j} / \mathrm{T}$ cps;

(2) the powers in the frequencies $(2 \mathrm{kn} \pm \mathrm{j}) / \mathrm{T}$ cps, $k=1,2, \ldots$;

(3) a part of the powers in the frequencies $1 /(\mathrm{m} T)$ cps, $m=2,3, \ldots$

The frequencies mentioned in (2) are called the 'aliases' to the frequency $j / T$ cps and the transfer of their powers to the frequency $j / T$ cps is well known. The study of the effect of the presence of frequencies lower than $1 / \mathrm{T}$ cps in the process on the harmonic analysis, however, seems to have been somewhat neglected. Spetner [1] considers the error in power spectra due to finite sample from a continuous Gaussian process, and to the author's knowledge no other references are found in the literature. The following results do not suppose the process to be Gaussian and the only restrictions placed on the process are given by equations (2.2) and (2.3).

\section{LOW FREQUENCIES IN THE PROCESS}

The record of $Y(t)$ over the interval of time $(0, T)$ can be exactly represented by

(2.1) $Y(t)=a_{0}+\sum_{j=1}^{\infty}\left(a_{j} \cos \frac{2 \pi j t}{T}+\beta_{j} \sin \frac{2 \pi j t}{T}\right)$. 
However, let the true representation of the process $Y(t)$ be

$$
\text { (2. 2) } \begin{aligned}
Y(t)= & \sum_{j=1}^{\infty}\left(a *(j) \cos \frac{2 \pi j t}{T}+\beta *(j) \sin \frac{2 \pi j t}{T} .\right) \\
& +\sum_{m=2}^{\infty}\left(a *\left(\frac{1}{m}\right) \cos \frac{2 \pi t}{m T}+\beta *\left(\frac{1}{m}\right) \sin \frac{2 \pi t}{m T}\right) .
\end{aligned}
$$

where $a *$ and $\beta$ * are random variables satisfying the following conditions:

(2. 3) $E a *(s)=E \beta *(s)=0$ for all index values of $s$,

$$
\begin{aligned}
& E_{a} *^{2}(s)=E \beta *^{2}(s)=\sigma *^{2}(s) \text {, } \\
& E_{a} *(s) a *(r)=E \beta *(s) \beta *(r)=0 \text { if } s \neq r \text {, } \\
& \mathbf{E} \alpha *(s) \beta *(\mathrm{r})=0 \text { for all } s \text { and } \mathrm{r} \text {, } \\
& \underset{s}{\Sigma} \sigma^{2}(s)=\sigma_{Y}^{2}<\infty \text {. }
\end{aligned}
$$

The power in the frequency $s / T$ cps is then defined as $\sigma *^{2}(s)$.

The conditions (2.3) are satisfied, for example, if the typical term of $(2.2)$ is represented by $\gamma_{g} \cos \left(\frac{2 \pi s t}{T}+\epsilon_{g}\right)$ and we assume $\gamma_{s}$ and $\epsilon_{8}$ to be independent variates with $E \gamma_{s}=0, E \gamma_{s}{ }^{2}=2 \sigma *{ }^{2}(s)$ and $\epsilon_{\mathrm{s}}$ to be distributed uniformly over the interval $(0,2 \pi)$.

Now, for $0<t<T$ 
(2.. 4) $\cos \frac{2 \pi t}{m T}=\frac{m}{2 \pi} \sin \frac{2 \pi}{m}-\frac{m}{\pi} \sin \frac{2 \pi}{m} \sum_{j=1}^{\infty}\left(j^{2} m^{2}-1\right)^{-1} \cos \frac{2 \pi j t}{T}$

$$
\begin{gathered}
+\frac{m^{2}}{\pi}\left(1-\cos \frac{2 \pi}{m}\right) \sum_{j=1}^{\infty} j\left(j^{2} m^{2}-1\right)^{-1} \sin \frac{2 \pi j t}{T} \\
\sin \frac{2 \pi t}{m T}=\frac{m}{2 \pi}\left(1-\cos \frac{2 \pi}{m}\right)-\frac{m}{\pi}\left(1-\cos \frac{2 \pi}{m}\right) \sum_{j=1}^{\infty}\left(j^{2} m^{2}-1\right)^{-1} \cos \frac{2 \pi j t}{T} \\
-\frac{m^{2}}{\pi} \sin \frac{2 \pi}{m} \sum_{j=1}^{\infty} j\left(j^{2} m^{2}-1\right)^{-1} \sin \frac{2 \pi j t}{T} .
\end{gathered}
$$

Since (2.1) and (2.2) are identical over the interval $(0, T)$,

we obtain

(2.5) $a_{0}=\sum_{m=2}^{\infty}\left[a *\left(\frac{1}{m}\right) \frac{m}{2 \pi} \sin \frac{2 \pi}{m}+\beta *\left(\frac{1}{m}\right) \frac{m}{2 \pi}\left(1-\cos \frac{2 \pi}{m}\right)\right]$.

and for $j>0$

(2.6) $a_{j}=a *(j)-\sum_{m=2}^{\infty}\left[a *\left(\frac{1}{m}\right)\left(j^{2} m^{2}-1\right)^{-1} \frac{m}{\pi} \sin \frac{2 \pi}{m}+\beta *\left(\frac{1}{m}\right)\left(j^{2} m^{2}-1\right)^{-1}\right.$

$$
\begin{gathered}
\left.\frac{m}{\pi}\left(1-\cos \frac{2 \pi}{m}\right)\right], \\
\beta_{j}=\beta *(j)+\sum_{m=2}^{\infty}\left[a *\left(\frac{1}{m}\right) j\left(j^{2} m^{2}-1\right)^{-1} \frac{m^{2}}{\pi}\left(1-\cos \frac{2 \pi}{m}\right)-\beta *\left(\frac{1}{m}\right) j\left(j^{2} m^{2}-1\right)^{-1} .\right. \\
\left.\frac{m^{2}}{\pi} \sin \frac{2 \pi}{m}\right] .
\end{gathered}
$$

We, therefore, have

(2.7) $E a_{j}=E \beta_{j}=0$ for $j=0,1, \ldots$ 
(2. 8)

$$
\begin{aligned}
& E a_{0}^{2}=\sum_{m=2}^{\infty} \sigma *^{2}\left(\frac{1}{m}\right) \frac{m^{2}}{\pi^{2}} \sin ^{2} \frac{\pi}{m}, \\
& E a_{j}^{2}=\sigma *^{2}(j)+4 \sum_{m=2}^{\infty} \sigma *^{2}\left(\frac{1}{m}\right) \frac{m^{2} \sin ^{2} \frac{\pi}{m}}{\pi^{2}\left(j^{2} m^{2}-1\right)^{2}} \text { for } j>0, \\
& E \beta_{j}^{2}=\sigma *^{2}(j)+4 \sum_{m=2}^{\infty} \sigma *^{2}\left(\frac{1}{m}\right) \frac{m^{4} j^{2} \sin ^{2} \frac{\pi}{m}}{\pi^{2}\left(j^{2} m^{2}-1\right)^{2}} \text { for } j>0, \\
& E a_{0} a_{j}=-2 \sum_{m=2}^{\infty} \sigma *^{2}\left(\frac{1}{m}\right) \frac{m^{2} \sin ^{2} \frac{\pi}{m}}{\pi^{2}\left(j^{2} m^{2}-1\right)} \text { for } j>0, \\
& E a_{i} a_{j}=4 \sum_{m=2}^{\infty} \sigma *^{2}\left(\frac{1}{m}\right) \frac{m^{2} \sin ^{2} \frac{\pi}{m}}{\pi^{2}\left(j^{2} m^{2}-1\right)\left(i^{2} m^{2}-1\right)} \text { for } i \neq j, i, j \neq 0, \\
& E \beta_{i} \beta_{j}=4 \sum_{m=2}^{\infty} \sigma *^{2}\left(\frac{1}{m}\right) \frac{m^{4} i j \sin ^{2} \frac{\pi}{m}}{\pi^{2}\left(j^{2} m^{2}-1\right)\left(i^{2} m^{2}-1\right)} \text { for } i \neq j, \\
& E a_{i} \beta_{j}=0 \quad \text { for all } i \text { and } j .^{\infty},
\end{aligned}
$$

Writing

$$
\sigma_{0}^{2}=E a_{0}^{2}, \sigma_{j}^{2}=\frac{1}{2} E\left(a_{j}^{2}+\beta_{j}^{2}\right) \quad \text { for } j>0,
$$

we find

$$
\text { (2.9) } \begin{aligned}
\sigma_{0}^{2} & =\sum_{m=2}^{\infty}\left(\frac{m}{\pi} \sin \frac{\pi}{m}\right)^{2} \sigma^{2}\left(\frac{1}{m}\right) . \\
\sigma_{j}^{2} & =\sigma *^{2}(j)+2 \sum_{m=2}^{\infty} \frac{j^{2} m^{2}+1}{\left(j^{2} m^{2}-1\right)^{2}}\left(\frac{m}{\pi} \sin \frac{\pi}{m}\right)^{2} \sigma *^{2}\left(\frac{1}{m}\right), \text { for } j>0 .
\end{aligned}
$$

5 
Performing the calculations so as to account for at least $90 \%$ of the power in each frequency, we have

$$
\begin{aligned}
& \sigma_{0}^{2}=0.405 \sigma * 2\left(\frac{1}{2}\right)+0.684 \sigma *^{2}\left(\frac{1}{3}\right)+0.811 \sigma *^{2}\left(\frac{1}{4}\right)+0.874 \sigma *^{2}\left(\frac{1}{5}\right) \\
& +0.912 \sigma *^{2}\left(\frac{1}{6}\right)+0.933 \sigma *^{2}\left(\frac{1}{7}\right)+0.950 \sigma *^{2}\left(\frac{1}{8}\right)+\theta \sum_{m=9}^{\infty} \sigma *^{2}\left(\frac{1}{m}\right) \\
& \text { where } 0.96<\theta<1 \text {, } \\
& \sigma_{1}^{2}=\sigma *^{2}(1)+0.450 \sigma * 2\left(\frac{1}{2}\right)+0.214 \sigma *^{2}\left(\frac{1}{3}\right)+0.123 \sigma *^{2}\left(\frac{1}{4}\right) \\
& +0.079 \sigma *^{2}\left(\frac{1}{5}\right)+\ldots . \\
& \sigma_{2}^{2}=\sigma^{2}(2)+0.061 \sigma^{2}\left(\frac{1}{2}\right)+0.041 \sigma *^{2}\left(\frac{1}{3}\right)+\ldots \\
& \sigma_{3}^{2}=\sigma *^{2}(3)+0.024 \sigma * *^{2}\left(\frac{1}{2}\right)+0.018 \sigma * *^{2}\left(\frac{1}{3}\right)+\ldots \\
& \sigma_{j}^{2} \cong \sigma *^{2}(j) \\
& \text { for } \mathrm{j} \geq 4
\end{aligned}
$$

We observe that more than $95 \%$ of the power in the frequencies lower than $1 /(7 T)$ cps is transferred to the zero frequency. Since the mean of the sample is usually subtracted from each observation before further analysis, the power $\sigma_{0}^{2}$ will be subtracted from the spectrum. Furthermore, more than $90 \%$ of the power in frequencies ranging from $\frac{1}{2 \mathrm{~T}}$ cps to zero cps is transferred to the zero and the first two lowest frequencies analysed.

\section{REFERENCE}

[1] Lee M. Spetner, "Errors in power spectra due to finite sample," Journal of Applied Physics 25 (1954), pp. 653-659. 


\section{THE NATIONAL BUREAU OF STANDARDS}

The scope of the scientific progran of the National Bureau of Standards at laboratory centers in Washington, D. C., and Boulder, Colorado, is given in the following outline:

Washington, D.C.

Electricity and Electronics. Resistance and Reactance. Electron Tubes. Electrical Instruments. Magnetic Mcasurements. Dielectrics. Engineering Electronics. Electronic Instrumentation. Electrochemistry.

Optics and Metrology. Photometry and Colorimetry. Optical Instruments. Photographic Technology. Length. Engineering Metrology.

Heat and Power. Tempcrature Physics. Thermodynamics. Cryogenic Physics. Rheology and Lubrication. Engine Fuels.

Atomic and Radiation Physies. Spectroscopy. Radiometry. Mass Spectrometry. Solid State Physics. Electron Physics. Atomic Physics. Nuclear Physics. Radioactivity. X-rays. Betatron. Nucleonic Instrumentation. Radiological Equipment. AEC Radiation Instruments.

Chemistry. Organic Coatings. Surface Chemistry. Organic Chemistry. Analytical Chemistry. Inorganic Chemistry. Electrodeposition. Gas Chemistry. Physical Chemistry. Thermochemistry. Spectrochemistry. Pure Substances.

Mechanics. Sound. Mechanical Instruments. Fluid Mechanics. Engineering Mechanics. Mass and Scale. Capacity, Density, and Fluid Meters. Combustion Controls.

Organic and Fibrous Materials. Rubber. Textiles. Paper. Leather. Testing and Specifications. Polymer Structure. Organic Plastics. Dental Research.

Metallurgy. Thermal Metallurgy. Chemical Metallurgy. Mechanical Metallurgy. Corrosion. Metal Physics.

Mineral Products. Engineering Ceramics. Glass. Refractories. Enameled Metals. Concreting Materials. Constitution and Microstructure.

Building Technology. Structural Engineering. Fire Protection. Air Conditioning. Heating, and Refrigeration. Floor, Roof, and Wall Coverings. Codes and Specifications. Heat Transfer.

Applied Mathematics. Numerical Analysis. Computation. Statistical Engineering. Mathematical Physics.

Data Processing Systems. SEAC Engineering Group. Components and Techniques. Digital Circuitry. Digital Systems. Analogue Systems. Application Engineering.

- Office of Basic Instrumentation

- Office of Weights and Measures

\section{Boulder, Colorado \\ BOULDER LABORATORIES \\ F. W. Brown, Director}

Cryogenic Engineering. Cryogenic Equipment. Cryogenic Processes. Properties of Materials. Gas Liquefaction.

Rodio Propagation Physics. Upper Atmosphere Research. Ionospheric Rescarch. Regular Propagation Services. Sun-Earth Relationships.

Radio Propagation Engineering. Data Reduction Instrumentation. Modulation Systems. Navigation Systems. Radio Noise. Tropospheric Mcasurements. Tropospheric Analysis. Radio Systems Application Engineering.

Radio Standards. High Frequency Electrical Standards. Radio Broadcast Service. High Frequency Impedance Standards. Calibration Center. Microwave Physics. Microwave Circuit Standards. 


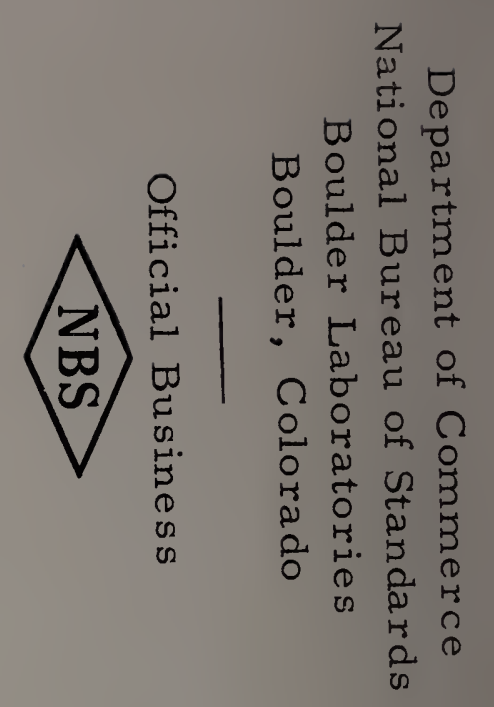

$C$

u

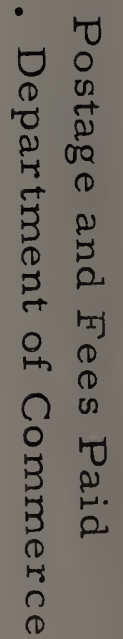

